\title{
Personal reflections on Jackson Pollock's fractal paintings
}

\section{Reflexões pessoais sobre as pinturas fractais de Jackson Pollock}

Richard Taylor

Associate Professor of Physics, Psychology, and Art Department of Physics, University of Oregon Eugene, OR 97403-1274 - USA

rpt@darkwing.uoregon.edu
TAYLOR, R.: Personal reflections on Jackson Pollock's fractal paintings.

História, Ciências, Saúde - Manguinhos, v. 13 (supplement), p. 108-23, October 2006.

The art world changed forever when Jackson Pollock picked up a can and poured paint onto a vast canvas rolled across the floor of his windswept barn. Fifty years on, art theorists recognize his patterns as being a revolutionary approach to aesthetics. A significant step forward in understanding Pollock's aesthetics occurred in 1999 when my scientific analysis showed that his paintings are fractal. Fractals consist of patterns that recur at finer and finer magnifications, building up shapes of immense complexity. Significantly, many natural patterns (for example, lightning, clouds, mountains, and trees) are also fractal. In this essay, I will present some personal reflections on this relationship between the fractal patterns of Pollock and those of nature, and also on the interactions between art and science as the project evolved.

KEYWORDS: Jackson Pollock; fractal; paintings; science and art.

TAYLOR, R.: Reflexões pessoais sobre as pinturas fractais de Jackson Pollock História, Ciências, Saúde - Manguinhos, v. 13 (suplemento), p. 108-23, outubro 2006.

O mundo da arte mudou para sempre quando Jackson Pollock apanhou uma lata e despejou tinta em uma enorme tela esticada sobre o chão de seu celeiro castigado pelo vento. Cinqüenta anos depois, os teóricos da arte reconhecem que seu estilo constitui uma abordagem estética revolucionária. Um passo importante na compreensão da estética de Pollock se deu em 1999, quando, de acordo com a minha análise científica, suas pinturas eram fractais. Fractais são padrôes que recorrem em sucessivos desdobramentos, construindo formas de imensa complexidade. Sugestivamente, muitos padrões naturais (como raios, nuvens, montanhas e árvores) também são fractais. No presente trabalho, apresento algumas reflexóes pessoais sobre essa relação entre os padrões fractais de Pollock e os da natureza, assim como sobre as interações entre arte e ciência.

PALAVRAS-CHAVE: Jackson Pollock; fractais; pintura; ciência e arte. 


\section{Pollock's rise to fame}

I begin my story of Fractal Expressionism with a description of the sketch by Ad Reinhart from 1946 called How to Look at Modern Art in America. The sketch consists of a tree with the names of prominent American artists from that era scrawled on the leaves, and the names of the European modern masters (Braque, Matisse, and Picasso) imprinted firmly on the trunk. The symbolism of the tree is clear - American modern art grows out of European modern art. Of course, it's not unusual for new art forms to grow from previous forms. However, Reinhart's sketch expressed a prevailing criticism that perhaps American modern art was uncomfortably close to copying. If you wanted to see something new, you should look towards Europe and not America.

This unfortunate circumstance was soon to change, and one of the artists responsible for the dramatic upswing in the originality of American art can be found on one of Reinhart's leaves. Born in 1912, Jackson Pollock was still relatively unknown in 1946, as reflected by the fact that his name was actually misspelled on his leaf! Art critics started to focus on Pollock in the late 1940s, around the time that the Hollywood film industry began to achieve international dominance. At this time, artists and art critics started to speculate whether America could achieve a similar dominance in the art world. More specifically, could the next movement in modern art originate in New York rather than Paris? For this to occur, it was clear that the American version of an artist would have to look distinctly different to their famous European counterparts. In this sense, Pollock was the right person at the right time. Whereas the European artists were sophisticated intellectuals, Pollock appeared in his battered boots, frequently drunk, and driving an old Ford truck. His colleague, Willem De Kooning, noted that Pollock looked more at home pumping gas than painting art, and he meant this as a compliment, not a criticism.

The Pollock story came under the public spotlight in 1949 when Life magazine asked the question, "Is he the greatest Living painter in the United States?" In this pre-television era, a Life magazine article was a significant event. An unprecedented number of readers wrote back declaring, quite passionately, that the answer was most definitely ... no! What caused this passionate public outcry? Several years earlier, Pollock had moved from downtown Manhattan to a small village at the tip of Long Island, New York, where he converted an old windswept barn into a studio, and within this studio he set about developing a truly revolutionary painting technique. Turning his back on the traditional, European artistic tools, he developed what became known as the 'pouring' or 'drip 
and splash' style. Abandoning the easel, he simply rolled his large canvases (sometimes spanning up to thirty feet long) across the floor of the studio. Rather than using a paintbrush to touch the canvas surface, he simply dipped it into a can and then poured paint directly onto the horizontal canvas below. Using this pouring technique he created vast, purely abstract images and in doing so he became the leading figure in an art movement known as Abstract Expressionism. The first modern art movement to originate in America, Abstract Expressionism shifted world focus from Paris to New York.

\section{Fractals, art, and nature}

Whereas the rise of the Abstract Expressionist movement made Pollock very popular within the circles of certain art critics, the public remained skeptical of his artistic achievements. This sentiment was captured nicely in a number of cartoons that appeared in the popular press at the time, in which the humorous imagery questioned not only whether Pollock was the greatest American artist but also whether he should be regarded as an artist at all. And the public wasn't alone in this worry - even Pollock was unsure as to whether he had pushed his painting technique too far and felt that perhaps his works shouldn't be regarded as paintings. Blue Poles, from 1952 (Figure 1), displays all of the

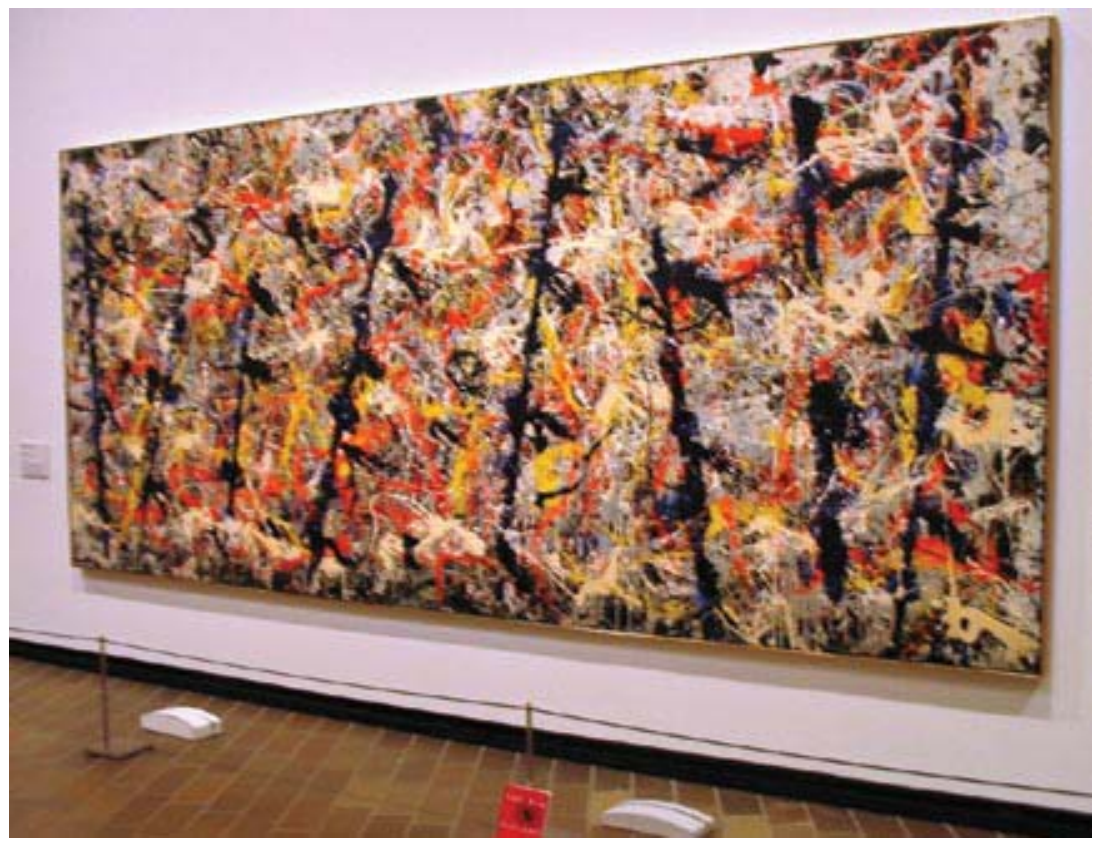

Figure 1: Pollock's Blue poles (The National Gallery of Australia), 1952.

Available at http://en.wikipedia.org/wiki/Image:BluePolesBigPicture.JPG 
'worrying' visual trademarks of Pollock's pouring process. The painting doesn't have an up or down, a left or right, or even a center of focus! In fact, Pollock's style is known formally as the "all-over style" due to the complete lack of focus of his compositions. Whereas these simple observations emphasize how far Pollock had deviated away from traditional artistic composition, they also provide the first clue as to what Pollock paintings are. Many of nature's patterns don't have ups or downs, lefts or rights, or centers of focus either. Figure 2 compares a natural pattern (that of tree roots) with one of Pollock's patterns (Number 32, from 1950). Although there are clearly superficial differences between the two images, a shared underlying quality shines through.

Not only is there a striking similarity between Pollock's patterns and those of nature, but there are also similarities between Pollock's painting process and the process used by nature to build its patterns. In particular, contrary to popular belief, Pollock didn't merely splatter a few blobs of paint on a canvas. Instead, he developed a cumulative painting process of returning to his canvas regularly, gradually building layer upon layer of poured paint. This is very similar to nature's processes - for example, the cliff face being carved out by the repeated pounding of the waves, or of the leaves falling day after day, building up a beautiful pattern. This link between Pollock and nature is not in itself a new observation. Two of Pollock's more famous quotes - "I am nature" and "My concerns are with the rhythms of nature" - serve as a springboard for such ideas. Furthermore, over the years, Pollock's work has often been referred to as 'organic', suggesting that his imagery alludes to nature. But what do we mean when we say a pattern looks organic? What do we know about nature's patterns?

The answer to this question lies in the world of mathematics. Since the 1860s, mathematicians have studied artificial shapes such as the L Snowflake shown in Figure 3. If we zoom in on the Koch
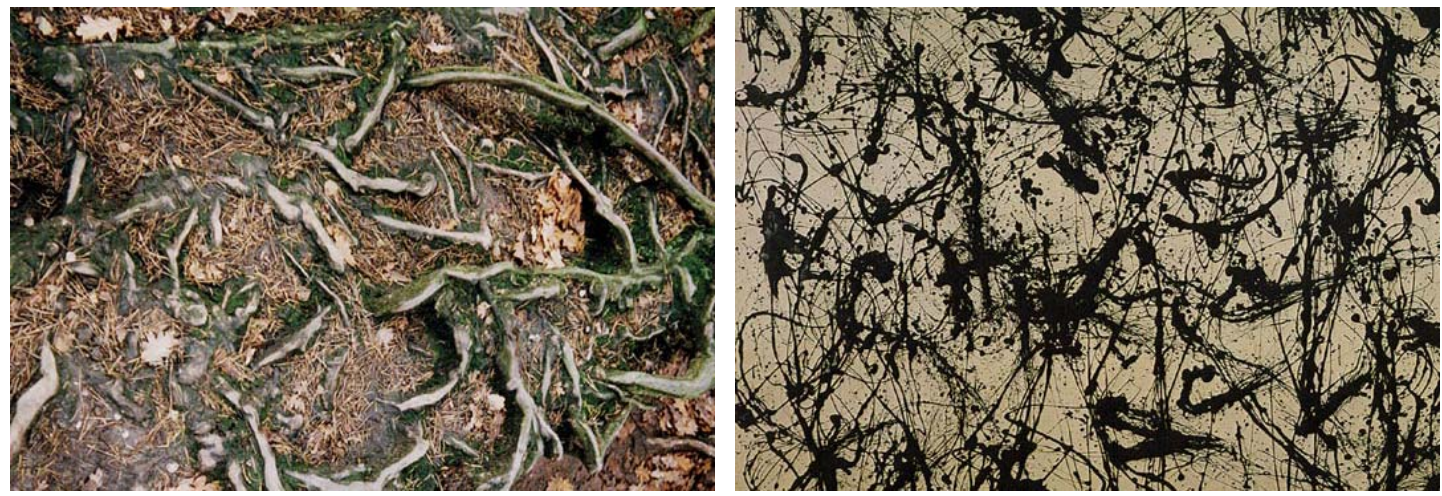

Figure 2: A comparison of image sections of tree roots and Pollock's Number 32, 1950, located at Kunstsammlung Nordrhein-Westfalen, Dusseldorf, Germany. 
Snowflake and compare the patterns that we observe at increasingly finer magnifications (in this case, three magnifications are considered), we find that the patterns are identical. This repetition of patterns at finer scales has since been labeled as 'fractal'. One of the consequences of this repletion is that it builds shapes of immense visual complexity. For a century, mathematicians referred to these shapes as 'pathological monsters' because their repeating patterns were assumed to have no connection with nature. Natural objects, such as coastlines and clouds, were recognized as being complex, but their complexity was thought to be the result of pure disorder - unlike the systematic pattern repetition that builds the fractal complexity displayed in Figure 3. However, the 1960s and 70s saw a renewed interest in the complexity of nature, and this cumulated in 1977 with Benoit Mandelbrot's epic work, "The Fractal Geometry of Nature", in which the complexity of many of nature's objects

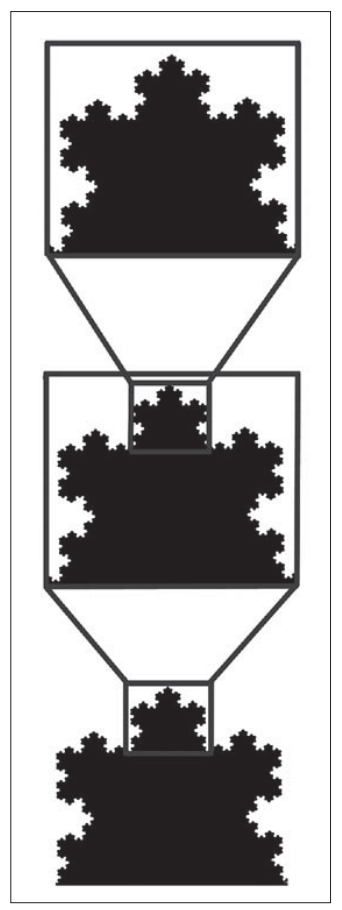

Figure 3: The Koch snowflake. Drawing made by the author. was shown to be the result of fractal repetition.

Figure 4 shows the difference between nature's fractals and their mathematical counterparts. The left-hand image shows a real tree built from nature's fractals. Although the images shown at the three magnifications aren't exactly the same, they look similar to each other because they share the same general (statistical) characteristics. These 'statistical' fractals of nature are clearly more subtle than the 'exact' fractals of the artificial tree shown in the right-hand image. Trees are perhaps the most common example of fractals that we meet in our daily lives. Mountains (with small peaks set on top of the larger peaks) are also fractal, as are waves crashing ashore, coastlines, lightning, clouds, and rivers. Aspects of human physiology are also built on fractals - fractals in our body include blood vessels, dendritic structure in the brain, and the lung's bronchial tree. In fact, fractals are so prevalent both inside and outside of our bodies that they've earned themselves the dramatic title of being the 'fingerprint of nature'. This generic quality of nature raises an essential question for Pollock's work: are fractal patterns responsible for the shared 'organic' appearance between nature and his paintings? If so, perhaps Pollock's work could be interpreted in terms of Pollock's ability to distill the very essence of natural scenery and express it on his canvases with a directness unmatched elsewhere in modern art. Remarkably, if this 
were the case, Pollock painted nature's fractals twenty-five years ahead of their scientific discovery!

\section{Fractal discoveries}

My entrance into the Pollock story was fueled by a different question. My scientific background lies in the study of electrical currents as they wind their way through the intricate circuits that lie at the heart of computers, compact disc players, televisions, and a range of other electronic devices. The circuits are built by linking together millions of small devices that are each about a million times smaller than a meter. Although small, the electricity flows through these devices in a well-controlled and orderly fashion. Fifteen years ago, technological improvements allowed myself and
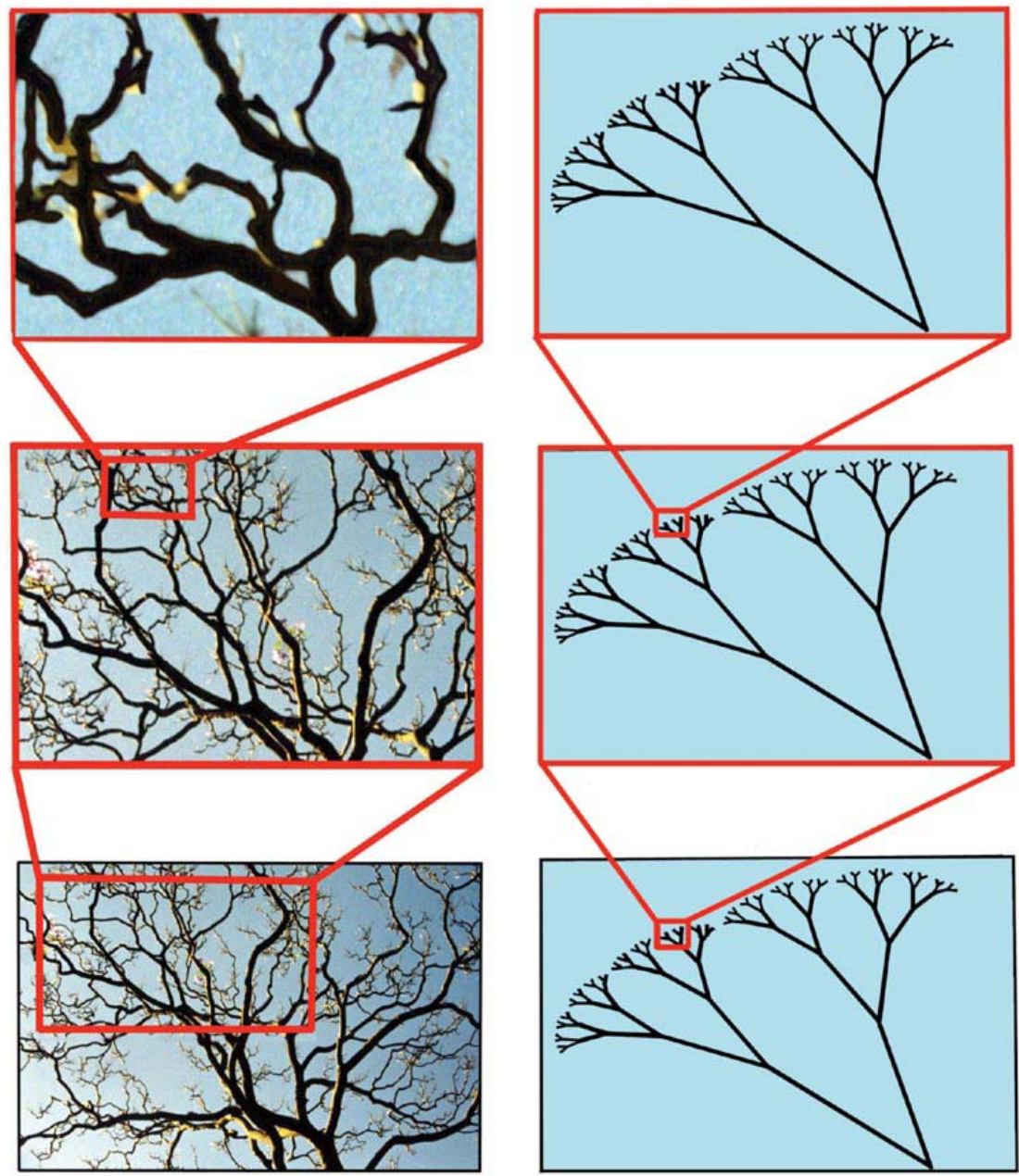

Figure 4: A comparison of statistical and exact fractal patterns. Drawing made by the author. 
others in my research field to construct 'nano-electronic' devices that are so small that they are only a factor of one hundred bigger than the size of atoms. At this scale, my research showed the electrical current stops being orderly and reverts back to natural behavior, spreading out in a fractal pattern (very similar to the branches of a tree) as the current passes through each device in the circuit. For this reason, my career gravitated towards research of fractals patterns - if I could understand the fractal currents, perhaps I could control and develop new electronic devices to make things faster and so more powerful.

Along the way, another question started to work on my mind: if scientific technology can be used to generate and control fractal patterns, is it possible for an artist to also achieve this? If so, was Pollock such an artist? This idea so fascinated me that in 1994 I decided to head off to the Manchester School of Art in England and explore this question further. In the bleakest winter month of February 1995, the school sent the students to the Yorkshire Moors in the north of England to paint the landscapes. However, a fantastic snowstorm blew in on the day we arrived, making it impossible to paint. That evening I retreated to a bar with a few friends to debate how to paint in this hostile environment. The answer came, not from Pollock, but from the French painter Yves Klein. I recalled a semi-fictional story of how Klein drove through a thunderstorm on the road from Paris to Toulouse. Attaching a canvas to the top of his car, the rain created a pattern on the canvas as he drove on. When he arrived in Toulouse, he framed the picture and sold it on the basis that nature had created art for him! Based on this story, we came up with the idea that we would also make nature paint for us!

That night we ventured out into the storm and assembled huge structures out of old tree branches blown over by the wind. The idea was fairly simple, as demonstrated by the pendulum structure shown in Figure 5. One part of the pendulum acted like a giant sail, catching the motions of the wind swirling around it. From my studies, I knew that these gusts of wind would be fractal. According to our plan, as the pendulum swayed through the air, this fractal motion would then be transferred to another part of the structure holding paint containers and these would drip a corresponding pattern onto a canvas on the ground. The following day the storm had passed and Figure 6 shows the painting that was left behind. Looking at this painting, the secrets of Jackson Pollock seemed to fall into place - the wind appeared to have painted a Pollock! Pollock must have adopted nature's fractal processes when he painted.

To confirm these speculations, I realized that I would have to head back into the world of science. Over the next five years (1995-99), 


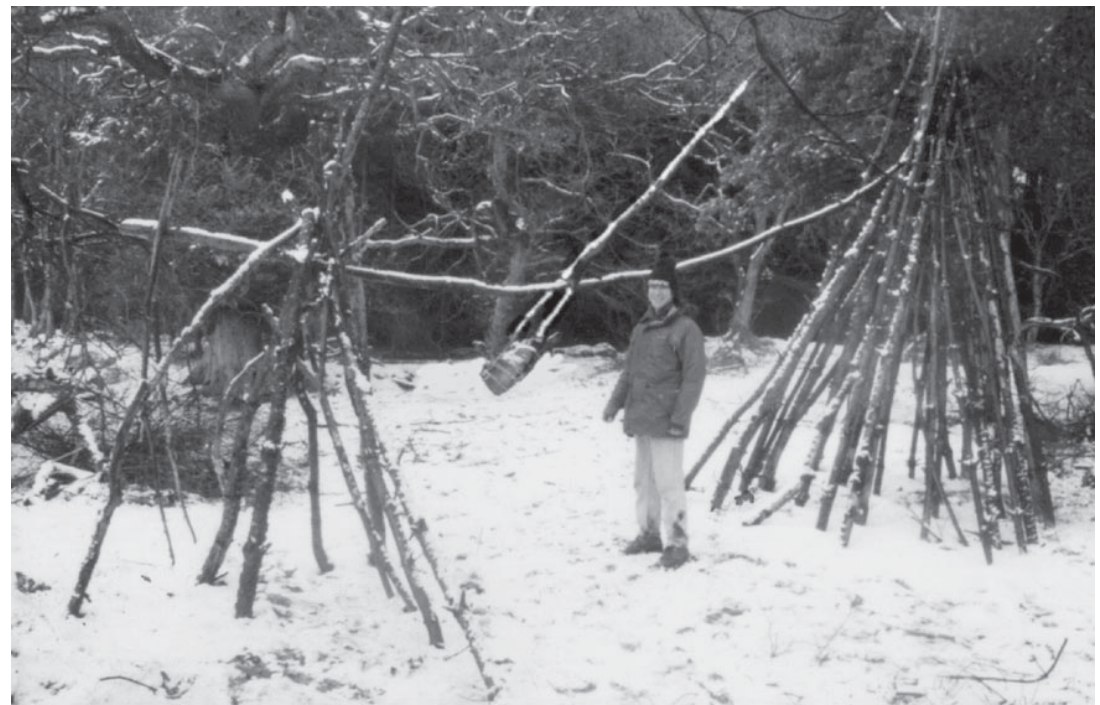

Figure 5: The wind-driven pendulum on the Yorkshire Moors in 1994. Author seen at photo by David Needham.

Figure 6: The poured painting produce by the pendulum. Produced on 17th March 1998 by the article's author.

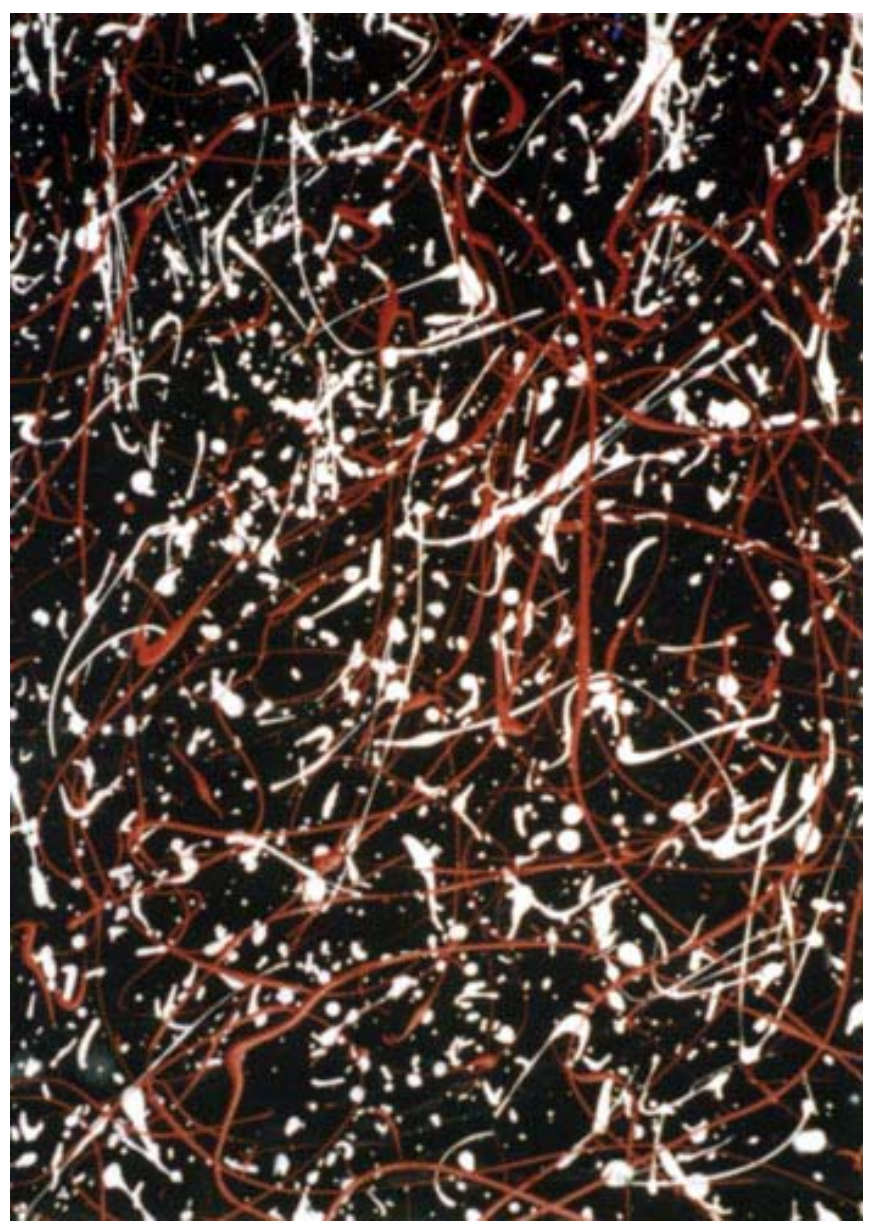


by day I researched the fractal electricity of nano-electronic devices and by night I researched Pollock's fractal paint patterns for a master's degree in art theory. Finally, in 1999, I published the results in Nature, describing the fractal character of Pollock's poured paintings. To check for fractals, I had used a computer to compare over five million patterns within a typical painting. This task would have been impossible for a person to do! In fact it is often said that the computer is to fractals what the microscope is to biology and what the telescope is to astronomy! This use of the computer might at first seem a harsh treatment of Pollock's paintings. After all, the computer doesn't care about art or about Pollock. It just treats the pattern as experimental data. However, it is in this scientific objectivity that the power of my procedure lies. The computer can look beyond Pollock mythology and identify the essence of his patterns - that they are fractal.

\section{Fractal expressionism}

To paint fractals is a remarkable achievement. Perhaps because of this, many works of art are labeled as being fractal. The claims stretch from Buddhist mandalas, to Islamic tiles, to the Gotland Stone in Sweden, through to Roman and Celtic designs. Particularly famous examples include the pencil sketch by Leonardo da Vinci from 1500 called The Deluge (where, within the turbulent swirls of water, you can clearly see smaller and smaller swirls) and The Great Wave by Katsushika Hokusai from 1846 (in which smaller waves sit on top of the great wave). Whereas these artists clearly noticed the recurring patterns of nature and were inspired to try to replicate them, these artworks are symbolic representations of fractals. They are not rigorously fractal in the sense that the computer would detect differences in the patterns at increasingly finer magnifications. In contrast, artworks generated by computer are as fractal as nature's patterns. Examples include The Mandelbrot Set (first generated by Mandelbrot in 1982, this fractal image has since become one of the best-known mathematical images of our time) and Fractal Forgeries (the name given to fractal scenery used to simulate natural landscapes for Hollywood movies). Pollock's paintings join this exclusive category - rather than mimicking fractals, his intricate patterns are as fractal as nature's patterns!

Significantly, Pollock didn't need a computer to generate his fractals. However, he isn't alone in this achievement. M. C. Escher was a remarkably gifted mathematician who possessed the skill and patience to meticulously embed fractal patterns into his beautiful designs. Elaborating on the common fractal character of Pollock and Escher's works, some journalists followed up on my Nature article by jokingly declaring Pollock to be a masterful 
mathematician! In contrast to Escher, Pollock of course painted his fractals with such a speed that the necessary calculations would be beyond even the most gifted mathematician. In reality, it seems that Pollock possessed an innate ability to generate fractals at a speed matched only by computers! To emphasize this fact, in early articles and public lectures I introduced the term 'Fractal Expressionism' to distinguish between the mathematical number crunching of computer-generated fractals and the more intrinsic, human source of Pollock's fractals. The intricacy, the precision, and the speed of Pollock's process suggested an astonishing talent. So much so that it seemed wise to look for a more mundane and believable explanation for his fractals, and an alternative quickly emerged. What if fractals are an inevitable consequence of pouring paint and that Pollock wasn't doing anything special at all? What if anyone could generate fractals by pouring paint?

Pollock supporters argued against this notion and predicted that anyone unwise enough to mimic Pollock's pouring technique would soon find themselves staring at an unpleasant mess devoid of fractals. We finally put this to the test in 2004 by asking thirtyseven students to participate in a controlled experiment. The students were supplied with materials similar to those used by Pollock and were asked to pour in the Pollock style. Two of the resulting paintings are shown in Figure 7 and demonstrate the remarkable variety that can be achieved with the pouring technique. It is clear from these images that the pouring process can be manipulated to steer away from the predicted 'unpleasant mess' and instead produce artist-specific patterns. However, are any of these patterns close to Pollock's fractals? The subsequent computer analysis revealed that none of the paintings matched the fractal characteristics found in Pollock's work, confirming that fractals are not an inevitable consequence of pouring paint but are instead the product of Pollock's particular technique.
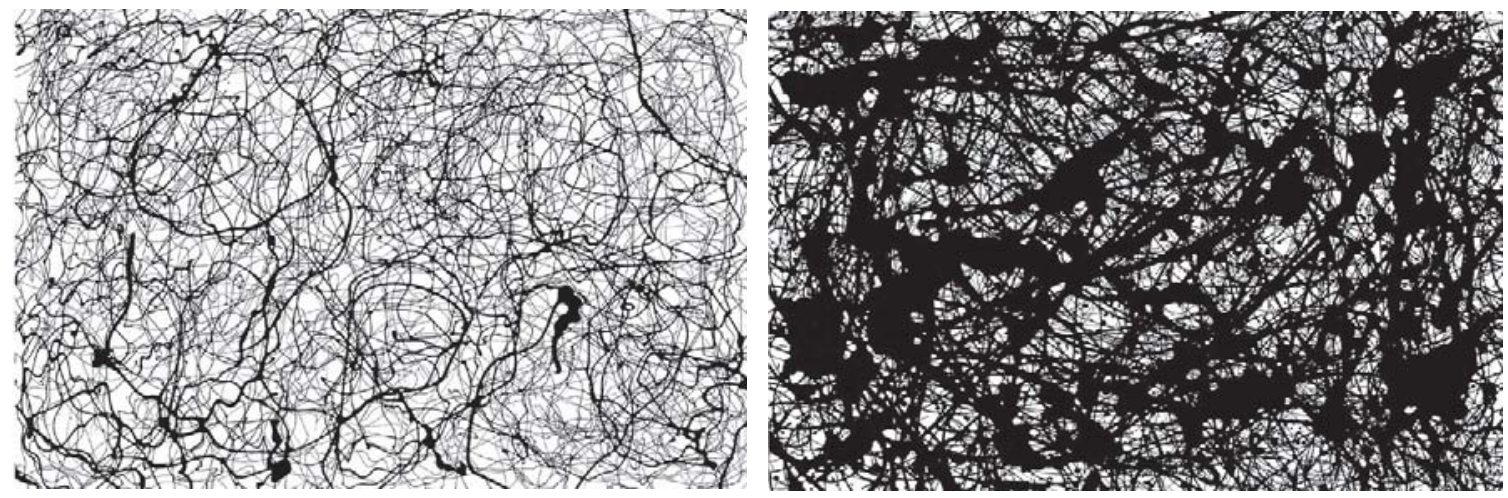

Figure 7: Two poured paintings produced by author's students in 2004. 
This view is further confirmed by examining well-known imitations of Pollock's work. Figure 8 shows a section from Pollock's Blue Poles and an equivalent section from a known imitation. Although the two poured patterns have a similar complexity, the computer analysis clearly reveals that, whereas the real Blue Poles is fractal, the imitation is not. In fact, I have had many opportunities to compare real and imitation Pollock paintings during the course of my research. There are approximately five hundred imitation paintings in the United States, and the traditional authenticity organizations (the Pollock-Krasner Foundation and the International Foundation for Art Research) have both used my fractal analysis technique in the process of distinguishing fakes from the real thing. This practical application of fractal analysis emphasizes the strong link between the fractal characteristics found in Pollock's paintings and Pollock's unique painting process.
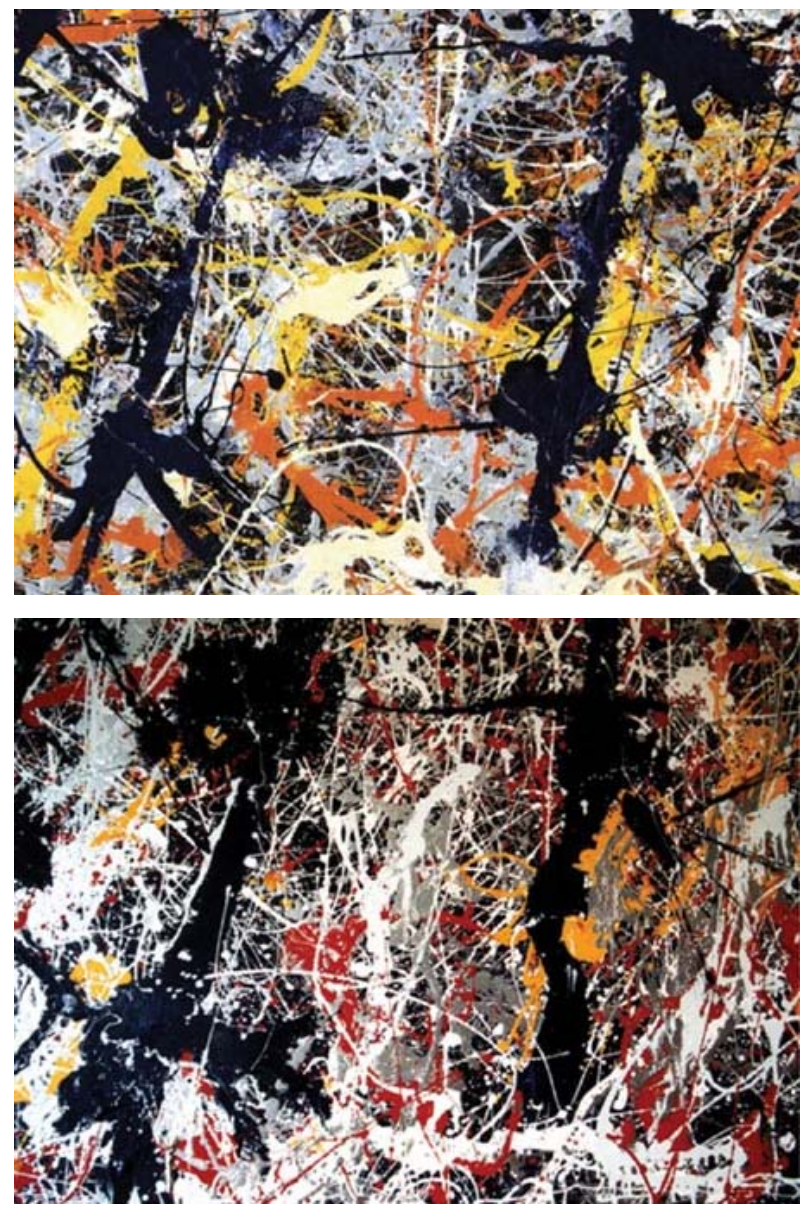

Figure 8: Close-up sections of Blue poles (top) and a replica (bottom). Photo taken by the article's author. The actual Blue Poles belongs to the collection at the National Gallery in Canberra, Australia. 


\section{Fractal aesthetics}

Pollock's friend, Ruebin Kadish, once noted, "I think that one of the most important things about Pollock's work is that it isn't so much what you're looking at but it's what is happening to you as you're looking at his particular work." What then are the visual consequences of Pollock's unique fractals and how do we respond to his unique artistic forms?

Perhaps surprisingly, the answers to these questions didn't emerge while taking tours through art galleries but instead were triggered by the construction of a mechanical apparatus that eventually became known as the 'Pollockizer'. The idea was inspired by the wind-driven pendulum (shown in Figure 5), and the initial experiments evolved in the freezing-cold of my parent's garage while attending Manchester School of Art in 1994-95. The Pollockizer is essentially a pendulum, in which a paint container is swung around on a piece of string. The paint container then pours paint onto a horizontal canvas laid out on the ground. The pendulum is no stranger to the art world. When left to swing on its own, the 'free pendulum' generates a very simple spiraling pattern. Instead, artists such as Max Ernst used to grab the pendulum and then steer the container through the air with their hands. This 'guided' pendulum generated poured patterns that served as inspirations for Ernst's Surrealist endeavors. In contrast, the Pollockizer is based on a 'forced pendulum', where the pendulum's string is knocked at regular intervals by a motor. By varying the rate at which the string is knocked, you can choose whether to generate fractal or non-fractal poured patterns on the canvas below. From its humble beginnings in the English winter of 1994, the Pollockizer rose to celebrity when it was filmed in action on the sunny coastline of Sydney, Australia, in 1998 (shown in Figure 9) and then broadcast on national television!

In visual perception experiments, I took fractal and non-fractal poured patterns generated by the Pollockizer and asked 120 people which they found to be the most visually appealing. Over $95 \%$ of the participants preferred fractal to non-fractal patterns. Perhaps this generic appreciation for fractal patterns explains Pollock's enduring success. Perhaps, also, it explains Pollock's motivation for developing a deliberate and systematic process for painting them. That Pollock's process was deliberate is suggested by the fact that the paint on his studio floor is not fractal. In other words, only the paint aimed at the canvas resulted in fractal patterns - fractals were a deliberate compositional tool of Pollock's. Furthermore, my analysis of film footage taken at Pollock's peak in 1950 reveals a remarkably systematic process. He started by painting localized islands of trajectories distributed across the canvas, followed by longer extended trajectories that joined the islands, gradually 


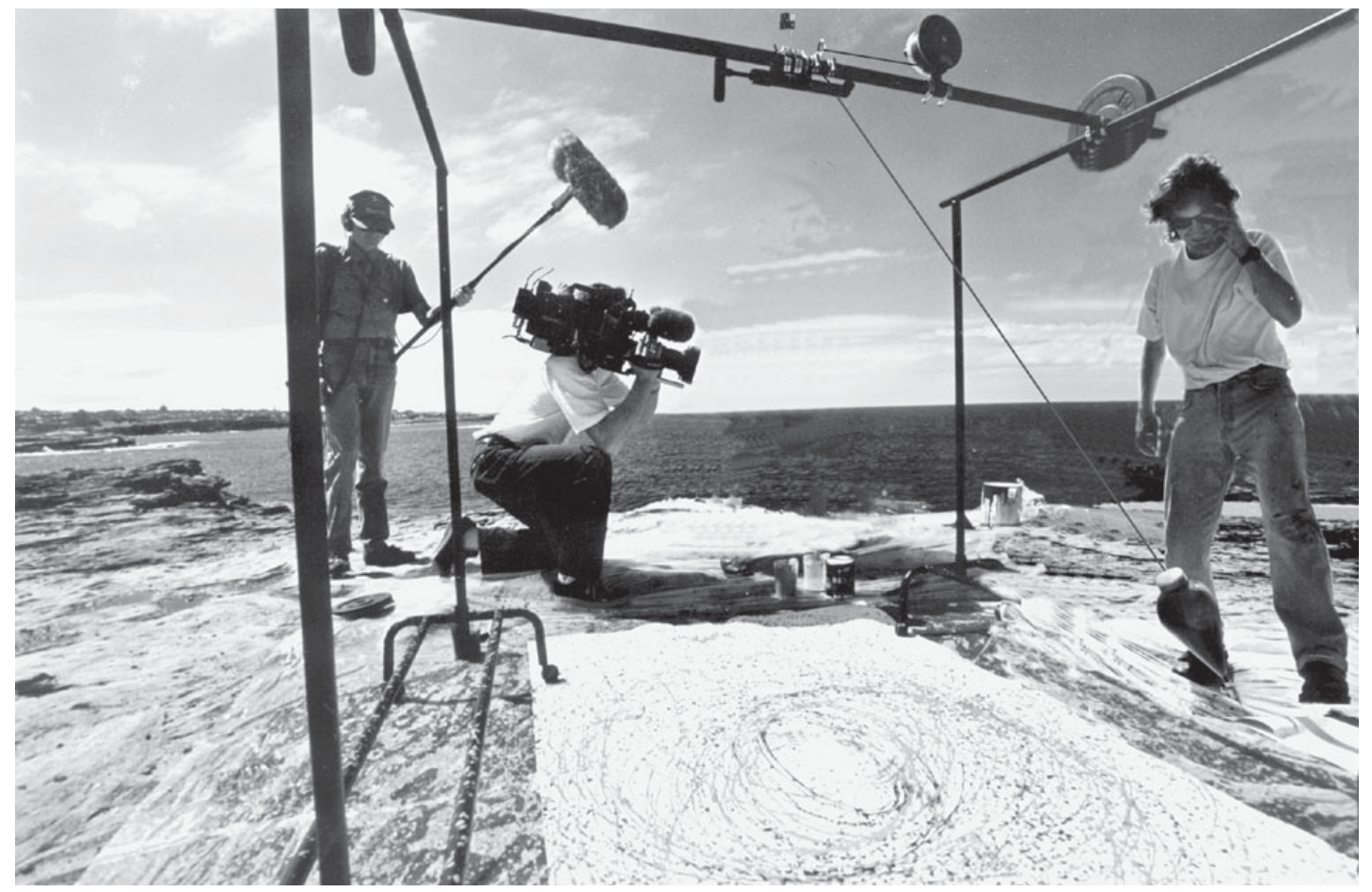

Figure 9: The Pollockizer being filmed by the Australian Broadcasting Company in 1998. Photo belongs to the author's collection.

submerging them in a dense fractal web of paint. He would then break off and later return to the painting over a period of several days, carefully depositing extra layers on top of this initial layer. Remarkably, Pollock's skill went beyond simply generating fractals - during the above process he was manipulating the fractal structure of his paintings to change their visual impact.

Perhaps the most important visual characteristic is the degree of complexity built up by the repeating patterns. This complexity is quantified by a parameter $D$ called the fractal dimension. Figure 10 shows a few visual examples of Pollock's fractals with different $D$ values. In essence, $D$ examines the relative amounts of course and fine patterns going into the fractal mix and quantifies the resulting complexity on a scale between one to two: fractal patterns with low $D$ values close to one have a very simple and sparse (low complexity) appearance and as $D$ rises closer to two, the patterns become more rich and intricate (high complexity). Through Pollock's life he was able to generate paintings with a range of different $D$ values, all of which correspond to various patterns found in nature. Significantly, as shown in Figure 10, the $D$ values of his painting evolved over the ten years that he perfected his technique. Art theorists categorize the evolution of Pollock's pouring technique into three phases. In the 'preliminary' phase of 1943-45, his initial 
efforts were characterized by low $D$ values. During his 'transitional phase' from 1945-47, he started to experiment with the poured technique and his $D$ values rose sharply (as indicated by the first gradient in Figure 10). In his 'classic' period of 1948-52, he perfected his technique and $D$ rose more gradually (second gradient in Figure 10) to the value of $D=1.7$. During his classic period he also painted Untitled (top image of Figure 10), which has an even higher $D$ value of 1.89 . However, he immediately erased this pattern (it was painted on glass), prompting the speculation that he regarded this painting as too complex, and immediately scaled back to paintings with $D=1.7$. This suggests that his ten years of refining the pouring technique were motivated by a desire to generate fractal patterns with mid-range complexity. Whereas this distinct evolution has been proposed as a way of authenticating and dating Pollock's work, it also raises a crucial question for visual scientists and artists alike: do these mid-complexity fractal patterns represent some sort of aesthetic ideal, a pattern that people are naturally drawn to?

Our experiments conducted over the last couple of years have revealed some fascinating results. In 2000, we conducted visual perception experiments on 220 participants using images based on nature's fractals, Pollock's fractals, and computer-generated fractals. The experiment showed that, irrespective of how the fractals were generated, there appears to be a universal preference for midcomplexity fractals. Does this visual appreciation have an impact on the physiological condition of the observer? In particular, could these patterns be used to reduce the observer's stress levels? In 2002, preliminary experiments based on skin conductance

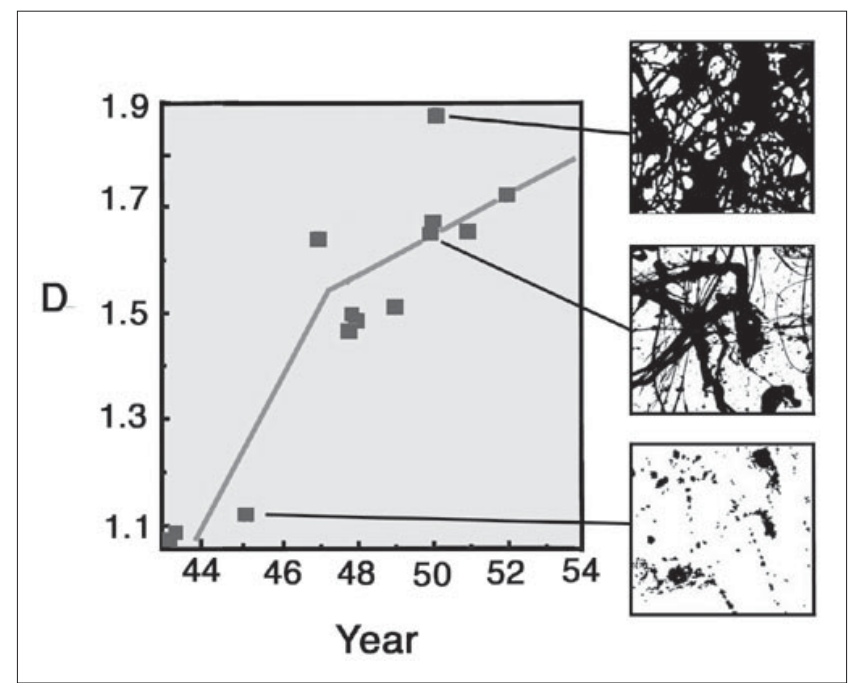

Figure 10: Fractal dimension $D$ plotted (by the article's author) as a function of the year the pattern was painted. The dashed line is a guide to the eye. 
Acknowledgments

The Addario Foundation and Research Corporation for financial support. This essay is dedicated to the memory of Jim Pugh, for the invaluable mix of humor and reality that he brought to our conversations about Pollock. measurements suggested that observers' physiological response to stress was reduced by sixty per cent for people looking at midcomplexity fractals. The results hold huge implications for societies around the world. For example, the United States spends approximately 300 billion dollars on stress-related illness every year, highlighting the potential of enhancing interiors and exteriors of buildings with Pollock-like fractal images. Pollock was one of the great modern painters of the twentieth century. The discussions in this essay suggest that he might have an even larger impact across society in the twenty-first century.

\section{FURTHER READING}

Mandelbrot, B. B. 1977

Taylor, R. P. 2003

Taylor, R. P. 2002

Taylor, R. P. 2001

Taylor, R. P.;

Micolich, A. P.; Jonas, D 2002

Taylor, R. P.;

Micolich, A. P.; Jonas, D. 1999 a

Taylor, R. P.;

Micolich, A. P.; Jonas, D. $1999 b$

Taylor, R. P. et al. 2005

Taylor, R. P. et al. [forthcoming]
The fractal geometry of nature.

New York: Freeman.

Fractal expressionism - where art meets science. In: Casti, J.; Karlqvist, A. (ed.) Art and complexity. Amsterdam: Elsevier Science.

Order in Pollock's chaos.

Scientific American, v. 287, p. 116-21, December.

Architect reaches for the clouds.

Nature, v. 410, p. 18.

The construction of Pollock's fractal drip paintings.

Leonardo, v. 35, n. 2, p. 203-7.

Fractal Analysis of Pollock's Drip Paintings.

Nature, v. 399, n. 22, p. 422.

Fractal expressionism: a scientific analysis of Jackson Pollock's drip paintings. Physics World, v. 25, v. 12, n. 10, p. 25, October.

Perceptual and physiological response to the visual complexity of fractals. The Journal of Nonlinear Dynamics, Psychology, and Life Sciences, v. 9 , n. 89 , p.115.

Authenticating Pollock paintings with fractal geometry.

To be published in Pattern recognition letters. 